\title{
Pleiotropic roles of iron-responsive transcriptional regulator Fur in Burkholderia multivorans
}

\author{
Correspondence \\ Masataka Tsuda \\ mtsuda@ige.tohoku.ac.jp
}

Received 1 December 2007

Revised 27 February 2008

Accepted 5 March 2008

\author{
Satoshi Yuhara, Harunobu Komatsu, Hiroyuki Goto, Yoshiyuki Ohtsubo, \\ Yuji Nagata and Masataka Tsuda
} Department of Environmental Life Sciences, Graduate School of Life Sciences, Tohoku University,
2-1-1 Katahira, Sendai 980-8577, Japan

\begin{abstract}
The fur (ferric uptake regulator) gene of Burkholderia multivorans ATCC 17616 was identified by transposon mutagenesis analysis. The fur deletion mutant of strain ATCC 17616 (i) constitutively produced siderophores, (ii) was more sensitive to reactive oxygen species (ROS) than the wild-type strain, (iii) showed lower superoxide dismutase and catalase activities than the wild-type strain, (iv) was unable to grow on M9 minimal agar plates containing several substrates that can be used as sole carbon sources by the wild-type strain, and ( $v$ ) was hypersensitive to nitrite and nitric oxide under microaerobic and aerobic conditions, respectively. These results clearly indicate that the Fur protein in strain ATCC 17616 plays pleiotropic roles in iron homeostasis, removal and/or resistance to ROS and nitrosative stress, and energy metabolism. Furthermore, employment of an in vivo Fur titration assay system led to the isolation from the ATCC 17616 genome of 13 Fur-binding DNA regions, and a subsequent electrophoretic mobility-shift assay confirmed the direct binding of Fur protein to all of these DNA regions. Transcriptional analysis of the genes located just downstream of the Fur-binding sites demonstrated that Fur acts as a repressor for these genes. Nine of the 13 regions were presumed to be involved in the acquisition and utilization of iron.
\end{abstract}

\section{INTRODUCTION}

The genus Burkholderia belongs to the Betaproteobacteria which have been isolated from various environments, including humans, animals, plants, water, rhizosphere and soils (Chiarini et al., 2006). While some strains in this genus are plant pathogens and opportunistic human pathogens (especially in cystic fibrosis patients), other strains have useful properties, e.g. the biocontrol of plant pathogens and the bioremediation of polluted environments (Parke \& Gurian-Sherman, 2001). Burkholderia multivorans is the second most common species in the so-called Burkholderia cepacia complex that is frequently associated with cystic fibrosis (Mahenthiralingam et al., 2005). This species is also prevalent in a diversity of natural environments, probably due to its broad metabolic capacity to use a number of carbon and nitrogen sources (Lessie et al., 1996). B. multivorans ATCC 17616 is a soil-

Abbreviations: CAS, Chrome Azurol S; (P)EB, (Poor) Environmental Bacteria (medium); ECF, extracytoplasmic function; EMSA; electrophoretic mobility-shift assay; Fur, ferric uptake regulator; FURTA, Fur titration assay; qRT-PCR, quantitative real-time reverse-transcription PCR; ROS, reactive oxygen species; SOD, superoxide dismutase.

The GenBank/EMBL/DDBJ accession numbers for the sequences reported in this paper are AP009835-AP009838.

Two supplementary tables with details of the PCR primer sequences and gene annotation are available with the online version of this paper. derived strain whose extraordinary metabolic versatility has been well analysed. As is the case in other Burkholderia strains, the ATCC 17616 genome has multiple replicons consisting of three chromosomes of 3.4, 2.5 and $0.9 \mathrm{Mb}$ (designated Chr I, Chr II and Chr III, respectively) and a $170 \mathrm{~kb}$ plasmid, pTGL1 (Cheng \& Lessie, 1994). This strain shows extensive genomic plasticity, exhibiting, for example, frequent and large-scale insertions and deletions (Lessie et al., 1996). Our previous investigations of this strain using Tn5-based transposon mutagenesis have also clarified the unique distribution of housekeeping and functional auxotrophic genes on both Chr I and Chr II (Komatsu et al., 2003; Nagata et al., 2005).

Iron is an essential element for the growth of almost all bacterial species. The solubility of ferric ion is very low in eukaryotic hosts as well as natural environments, and bacteria have evolved various kinds of efficient mechanisms to acquire iron under limiting conditions. However, a high concentration of intracellular iron is very toxic under aerobic conditions, and intracellular ferrous iron, for example, reacts with metabolically produced $\mathrm{H}_{2} \mathrm{O}_{2}$ to generate a highly toxic and reactive hydroxyl radical by the Fenton reaction (Andrews et al., 2003). Therefore, many bacteria have their own systems to strictly maintain intracellular iron homeostasis, and one of the key regulator proteins for this homeostasis is an iron-responsive 
transcriptional regulator, Fur (ferric uptake regulator). The Fur protein binds to specific sequences (Fur boxes), and under iron-rich conditions, usually represses the transcription of genes located downstream of Fur boxes (Escolar et al., 1999). Although many of these genes specify functions for the acquisition and utilization of iron, Fur proteins in pathogenic bacteria have also been shown to function as global regulators for (i) removal of reactive oxygen species (ROS) (Thompson et al., 2002; Touati et al., 1995), (ii) production of virulence factors (Litwin \& Calderwood, 1993; Mey et al., 2005), (iii) acid tolerance (Hall \& Foster, 1996), (iv) formation of biofilms (Banin et al., 2005), and (v) removal of reactive nitrogen species (Abdul-Tehrani et al., 1999; Mukhopadhyay et al., 2004). Fur is further considered to have essential but unknown function(s) in some bacterial strains because null mutants have not been obtained despite repeated attempts. Pseudomonas aeruginosa is one such bacterium, and analysis of a fur point mutant in this species has revealed that its wild-type Fur protein most probably regulates the expression of various genes, including those involved in the catabolism of carbon sources, and aerobic and anaerobic respiration (Vasil, 2007).

Fur proteins in the genus Burkholderia have been predicted to play pleiotropic roles in the regulation of genes for iron acquisition, intracellular iron storage and release, and removal of ROS (Loprasert et al., 2000; Lowe et al., 2001; Tuanyok et al., 2005). However, it remains unclear whether Fur is definitely involved in all of these roles. This is because no null mutants of fur have been obtained, and in the case of Burkholderia pseudomallei, such a mutant has been considered to be lethal for (an) unknown reason(s) (Loprasert et al., 2000). We have indicated in this study that the Fur function in B. multivorans ATCC 17616 is not essential for the growth and/or viability of the cells. Subsequent analysis of a fur deletion mutant clearly demonstrated that the Fur protein in ATCC 17616 is pleiotropically involved in iron homeostasis, removal of ROS, and carbon and nitrogen metabolism.

\section{METHODS}

Bacterial strains, plasmids and media. The bacterial strains and plasmids used in this study are listed in Table 1. Escherichia coli cells were cultivated at $37^{\circ} \mathrm{C}$ and $\mathrm{B}$. multivorans cells at $30^{\circ} \mathrm{C}$. AnaeroPack-Anaero and AnaeroPack-Microaero systems (Mitsubishi Gas Chemical) were used for cultivation of B. multivorans under anaerobic and microaerobic $\left(5 \% \mathrm{O}_{2}\right)$ conditions, respectively. The liquid media used were Luria-Bertani (LB) broth (Ausubel et al., 1991), Environmental Bacteria (EB) broth $\left(1^{-1}: 3.3\right.$ g Bacto Tryptone, 1.7 g yeast extract, $5 \mathrm{~g} \mathrm{NaCl}$ ), Poor EB (PEB) broth $\left(1^{-1}: 1 \mathrm{~g}\right.$ Bacto Tryptone, $0.5 \mathrm{~g}$ yeast extract, $5 \mathrm{~g} \mathrm{NaCl}$ ) and $\mathrm{M} 9$ minimal medium with an appropriate carbon source at $0.2 \%(\mathrm{w} / \mathrm{v})$. Solid media were prepared by the addition of $1.5 \%(\mathrm{w} / \mathrm{v})$ agar. The production of

Table 1. Bacterial strains and plasmids used in this study

\begin{tabular}{|c|c|c|}
\hline Strain/plasmid & Relevant characteristics & Reference or source \\
\hline \multicolumn{3}{|l|}{ E. coli } \\
\hline DH5 $\alpha$ & recA1 endA1 gyrA96 thi-1 hsdR17 supE44 $\Delta($ lac) U169 ( $\phi 80 \mathrm{~d} l a c \Delta M 15)$ & Ausubel et al. (1991) \\
\hline BL21(DE3) & $\mathrm{F}^{-}$ompT hsdS ${ }_{B}\left(\mathrm{r}_{\mathrm{B}}^{-} \mathrm{m}_{\mathrm{B}}^{-}\right)$gal dcm $\lambda(\mathrm{DE} 3)$ & Studier \& Moffatt (1986) \\
\hline H1780 & fur fiu: : $\lambda$ placMu & Hantke (1987) \\
\hline H1717 & aroB fhuF: : $\lambda$ placMu & Hantke (1987) \\
\hline JM109 ( $\lambda$ pir) & $\lambda$ pir lysogen of JM109 & Lab collection \\
\hline \multicolumn{3}{|l|}{ B. multivorans } \\
\hline ATCC 17616 & Soil isolate; type strain & ATCC \\
\hline BT163 & $\mathrm{Tp}^{\mathrm{r}}$; ATCC 17616 fur::TnMod-RTp' & This study \\
\hline DF1 & $\mathrm{Cm}^{\mathrm{r}}$; ATCC 17616 fur deletion mutant & This study \\
\hline \multicolumn{3}{|l|}{ Plasmids } \\
\hline pTnMod-RTp' & $\begin{array}{l}\mathrm{Tp}^{\mathrm{r}} \text {; TnMod-RTp' -containing plasmid whose transposable region carries the } \mathrm{Tp}^{\mathrm{r}} \text { gene and } \\
\text { R6KoriV }\end{array}$ & Dennis \& Zylstra (1998) \\
\hline pEX18Tc & $\begin{array}{l}\mathrm{Tc}^{\mathrm{r}} \text { sacB oriT; suicide vector for gene replacement carrying the pUC18-derived } \\
\text { multiple-cloning sites }\end{array}$ & Hoang et al. (1998) \\
\hline pACYC184 & $\mathrm{Cm}^{\mathrm{r}}$; plasmid vector & Chang \& Cohen (1978) \\
\hline pTrc99A & $\mathrm{Ap}^{\mathrm{r}}$; expression vector & Amann \& Brosius (1985) \\
\hline pHSG398 & $\mathrm{Cm}^{\mathrm{r}}$; plasmid vector & Takeshita et al. (1987) \\
\hline pME6041 & $\mathrm{Km}^{\mathrm{r}}$; shuttle vector able to replicate in E. coli and B. multivorans & Heeb et al. (2000) \\
\hline pT7Blue-T & Ap $^{r} ;$ T-vector & Novagen \\
\hline pColdIV & $\mathrm{Ap}^{\mathrm{r}}$; cold-shock expression vector under the control of the $\operatorname{csp} A$ promoter and $l a c I^{\mathrm{q}}$ & Qing et al. (2004) \\
\hline pFur & Ap $^{r}$; pT7Blue-T containing the ATCC 17616 fur gene & This study \\
\hline pDF1 & $\mathrm{Tc}^{\mathrm{r}} \mathrm{Cm}^{\mathrm{r}}$; pEX18Tc containing $5^{\prime}$-flanking region of fur $-\mathrm{Cm}^{\mathrm{r}}$ gene- $3^{\prime}$-flanking region of fur & This study \\
\hline pCF1 & $\mathrm{Km}^{\mathrm{r}}$; pME6041 derivative with the KpnI-PstI fur-containing fragment from pFur & This study \\
\hline pEF1 & $\mathrm{Ap}^{\mathrm{r}}$; pTrc99A derivative with the KpnI-HindIII fur-containing fragment from pFur & This study \\
\hline pEF2 & $\mathrm{Ap}^{\mathrm{r}}$; pColdIV containing the ATCC 17616 fur gene & This study \\
\hline
\end{tabular}


siderophores was monitored on Chrome Azurol S (CAS) agar prepared by adding $10 \mathrm{ml}$ CAS reagent (Schwyn \& Neilands, 1987) to $90 \mathrm{ml} \mathrm{PEB}$ agar. For iron-rich and iron-limiting conditions, $\mathrm{FeCl}_{3}$ and 2,2-dipyridyl were added to the medium at final concentrations of 30 and $100 \mu \mathrm{M}$, respectively. When needed, IPTG and X-Gal were used at final concentrations of $0.5 \mathrm{mM}$ and $40 \mu \mathrm{M}$, respectively. Antibiotics were added to media at the following concentrations: (for E. coli) $100 \mu \mathrm{g}$ ampicillin (Ap) $\mathrm{ml}^{-1}, 100 \mu \mathrm{g}$ chloramphenicol $(\mathrm{Cm})$ $\mathrm{ml}^{-1}, 50 \mu \mathrm{g}$ kanamycin $(\mathrm{Km}) \mathrm{ml}^{-1}, 10 \mu \mathrm{g}$ tetracycline (Tc) $\mathrm{ml}^{-1}$, $200 \mu \mathrm{g}$ trimethoprim (Tp) $\mathrm{ml}^{-1}$; (for B. multivorans) $100 \mu \mathrm{g} \mathrm{Cm}$ $\mathrm{ml}^{-1}, 100 \mu \mathrm{g} \mathrm{Km} \mathrm{ml}^{-1}, 50 \mu \mathrm{g} \mathrm{Tc} \mathrm{ml}{ }^{-1}, 100 \mu \mathrm{g} \mathrm{Tp} \mathrm{ml}{ }^{-1}$.

Carbon assimilation tests. Cells grown to late exponential phase in PEB broth were washed three times with M9 minimal solution and diluted approximately $5 \times 10^{1}$ to $5 \times 10^{8}$ c.f.u. $\mathrm{ml}^{-1}$ using the same solution. A $5 \mu \mathrm{l}$ aliquot of cell suspension was spotted onto EB and M9 minimal agar plates containing an appropriate carbon source. The number of c.f.u. was assessed after incubation at $30{ }^{\circ} \mathrm{C}$ for 4 days.

The oxidation of 95 different carbon compounds by B. multivorans cells was also examined using a Biolog GN2 microtitre-plate system. The cells grown to the late exponential phase in PEB broth were collected, washed three times with M9 minimal solution, and diluted in the same solution to an $\mathrm{OD}_{660}$ of 0.25 . A $150 \mu \mathrm{l}$ aliquot of cell suspension was dispersed into each well of the microtitre plate. When the carbon compound in the well is a substrate of cellular respiration that generates electrons, the colourless tetrazolium dye is reduced, giving rise to a purple colour. The purple coloration of each well was examined after incubation at $30{ }^{\circ} \mathrm{C}$ for $24 \mathrm{~h}$.

Sensitivity of $B$. multivorans cells to $\mathrm{H}_{2} \mathrm{O}_{2}$, paraquat and nitrogen compounds. The sensitivity of cells to two ROSs, $\mathrm{H}_{2} \mathrm{O}_{2}$ and superoxide, was examined as follows. A late-exponential-phase culture was spread onto EB plates onto which were placed disks supplemented with $10 \mu \mathrm{l} 30 \% \mathrm{H}_{2} \mathrm{O}_{2}(\mathrm{v} / \mathrm{v})$ or $100 \mu \mathrm{M}$ paraquat (a superoxide generator). The plates were incubated at $30{ }^{\circ} \mathrm{C}$ for $36 \mathrm{~h}$, and the diameters of the growth inhibition zones surrounding the disks were measured. To assess the sensitivity to nitrate, nitrite or acidified nitrite [a nitric oxide ( $\mathrm{NO}$ ) producer], late-exponentialphase cells were diluted to approximately $5 \times 10^{3}-5 \times 10^{8}$ c.f.u. $\mathrm{ml}^{-1}$ in fresh EB broth. A $10 \mu \mathrm{l}$ aliquot of cell suspension was spotted onto an $\mathrm{EB}$ agar plate containing $10 \mathrm{mM}$ potassium nitrate or $5 \mathrm{mM}$ sodium nitrite. The sensitivity to the two nitrogen compounds was assessed by measuring the number of c.f.u. after incubation at $30{ }^{\circ} \mathrm{C}$ for $48 \mathrm{~h}$ under aerobic, anaerobic and microaerobic conditions. Since the growth of neither strain ATCC 17616 nor its fur deletion mutant (DF1) was detected on agar plates supplemented with acidified nitrite, their growth rates were measured using liquid media. Cells grown to late exponential phase (approx. $1 \times 10^{9}$ c.f.u. $\mathrm{ml}^{-1}$ ) were diluted 100 fold in fresh EB broth with or without $2 \mathrm{mM}$ acidified nitrite, cultivated at $30{ }^{\circ} \mathrm{C}$, and the $\mathrm{OD}_{660}$ was monitored by using a BioPhotorecorder TVS062CA (Advantec). Because the ATCC 17616 cells grew very slowly in the presence of nitrite under anaerobic conditions, the microanaerobic condition was employed to examine the sensitivity of $B$. multivorans cells to nitrite.

Native PAGE and staining for superoxide dismutase (SOD) and catalase activities. Mid-exponential-phase cells were disrupted by sonication with a Branson Sonifer for $1 \mathrm{~min}$, and their lysates were recovered by centrifugation at $13000 \mathrm{~g}$ for $10 \mathrm{~min}$. The resulting supernatants were subjected to electrophoresis in $10 \%(\mathrm{w} / \mathrm{v})$ native polyacrylamide gel. Total protein concentrations were estimated by using a Bradford colorimetric assay system (Bio-Rad). SOD and catalase activities were examined as described by Lefebre \& Valvano (2001).

Basic DNA and RNA manipulations, construction of plasmids, and allelic exchange mutagenesis. Established protocols were used for the preparation of genomic and plasmid DNA, DNA digestion with restriction endonucleases, ligation, standard agarose gel electrophoresis, DNA sequencing, and transformation of E. coli and B. multivorans cells (Komatsu et al., 2003; Sambrook \& Russell, 2001). PCR was performed with ExTaq DNA polymerase (Takara) or KOD -Plus- DNA polymerase (Toyobo). To measure the mRNA level of each gene in B. multivorans cells, an Isogen kit (Nippon Gene) was used to isolate the total RNA fraction from mid-exponential-phase cells in liquid culture. Reverse transcription was carried out using an RNA PCR kit (AMV) version 3 (Takara). The cDNA was used to carry out quantitative real-time reverse-transcription PCR (qRT-PCR) using an Opticon 2 system (Bio-Rad) and SYBR Premix ExTaq (Takara) in a reaction volume of $10 \mu$. The transcript level of the $B$. multivorans dnaA gene was used as the internal standard.

A pHSG398-based library of the ATCC 17616 genome was constructed by partial digestion of the genomic DNA with Sau3AI, ligation of the restricted fragments with BamHI-treated pHSG398 DNA and subsequent transformation of DH5 $\alpha$. The library consisted of approximately $9 \times 10^{4}$ clones, and the mean size of inserts was 460 bp.

Cloning of the TnMod-RTp' -containing genomic region from BT163 was carried out by digestion of its genomic DNA with EcoRI or SphI (which is absent from TnMod-RTp'), self-ligation and transformation of JM109( $\lambda$ pir) to select the $\mathrm{Tp}^{\mathrm{r}}$ clones. The wild-type fur-containing fragment of strain ATCC 17616 was amplified by PCR using the primer set FURF and FURR (see supplementary Table S1, available with the online version of this paper) and cloned into the pT7Blue T-vector (Novagen). The resulting plasmid (pFur) was digested by $K p n \mathrm{I}$ and PstI, and the DNA fragment containing fur was recloned into pME6041 to obtain pCF1. The wild-type fur-containing fragment of strain ATCC 17616 was also amplified by PCR using another primer set, FUR-F-BAMHI and FUR-R-HINDIII-NDEI (see supplementary Table S1), and cloned into the NdeI-BamHI sites of pColdIV to construct pEF2.

To remove the fur gene from the ATCC 17616 genome, the three primer sets shown in supplementary Table S1 were used to amplify the following three fragments by PCR: the fur upstream region flanked by EcoRI and BamHI sites at the 5' and $3^{\prime}$ ends, respectively; the $\mathrm{Cm}^{\mathrm{r}}$ gene fragment from pACYC184 flanked by BamHI sites; and the fur downstream region flanked by BamHI and HindIII sites at the $5^{\prime}$ and $3^{\prime}$ ends, respectively. The upstream and downstream fragments were sequentially cloned into the EcoRI-BamHI and BamHI-HindIII sites, respectively, of pEX18Tc, and the $\mathrm{Cm}^{\mathrm{r}}$ gene fragment was finally inserted into the BamHI site of the pEX18Tc derivative. The resulting plasmid (pDF1) was introduced into strain ATCC 17616 by electroporation to select the transformants that showed resistance to both $\mathrm{Cm}$ and $5 \%(\mathrm{w} / \mathrm{v})$ sucrose. The expected double-crossovermediated homologous recombination in the transformants was confirmed by PCR. One of these transformants completely lacked the fur gene and was designated DF1.

Measurement of LacZ activities. LacZ activities were measured as described previously (Ohtsubo et al., 2006).

Isolation Fur-binding sequences from the $B$. multivorans genome. The isolation of Fur-binding DNA sequences was carried out according to the Fur titration assay (FURTA) system developed by Stojilikovic et al. (1994). The pHSG398-based genomic library from ATCC 17616 was introduced into E. coli H1717 to select the $\mathrm{Cm}^{\mathrm{r}}$ transformants on MacConkey lactose agar plates containing $30 \mu \mathrm{M} \mathrm{FeCl}_{3}$. Colonies exhibiting red coloration after $24 \mathrm{~h}$ incubation at $37{ }^{\circ} \mathrm{C}$ were purified on the same selective plates, and the plasmids residing in such colonies were predicted to contain the $B$. multivorans DNA sequences that bind the E. coli Fur protein with high affinities. 
Purification of Fur protein and electrophoretic mobility-shift assay (EMSA) of the Fur-binding DNA sequence. E. coli BL21(DE3) cells carrying pEF2 were cultivated in LB at $37^{\circ} \mathrm{C}$ to an $\mathrm{OD}_{660}$ of 0.6 . The culture was kept at $15{ }^{\circ} \mathrm{C}$ for $30 \mathrm{~min}$, and IPTG was added to a final concentration of $1 \mathrm{mM}$. After cultivation at $15{ }^{\circ} \mathrm{C}$ for $24 \mathrm{~h}$, the cells were harvested by centrifugation and suspended in sonication buffer [50 mM Tris/HCl ( $\mathrm{pH} 7.5), 200 \mathrm{mM} \mathrm{KCl,} 5 \mathrm{mM}$ $\mathrm{MgCl}_{2}, 10 \%$ (w/v) glycerol]. The cells were disrupted by sonication using a Multi-Bead Shocker (Yasui). After centrifugation $(20000 \mathrm{~g})$ at $4{ }^{\circ} \mathrm{C}$ for $15 \mathrm{~min}$, the protein fraction in the supernatant was concentrated by $30 \%(\mathrm{w} / \mathrm{v})$ ammonium sulfate precipitation, and dialysed against storage buffer $[50 \mathrm{mM}$ Tris/ $\mathrm{HCl}(\mathrm{pH}$ 7.5), $200 \mathrm{mM}$ $\mathrm{KCl}, 5 \mathrm{mM} \mathrm{MgCl}, 500 \mu \mathrm{M} \mathrm{MnCl}_{2}, 50 \%$ (w/v) glycerol]. The Fur protein in the fraction was more than $90 \%$ pure based on SDS-PAGE analysis (data not shown).

The DNA fragments to be investigated were PCR-amplified and endlabelled with $\left[\gamma_{-}{ }^{32} \mathrm{P}\right] \mathrm{ATP}$ by using T4 polynucleotide kinase, and a $100 \mathrm{pM}$ aliquot of the end-labelled DNA fragments was solubilized in $10 \mu$ binding buffer $[10 \mathrm{mM}$ Tris/ $\mathrm{HCl}(\mathrm{pH} 7.5), 40 \mathrm{mM} \mathrm{KCl}, 1 \mathrm{mM}$ $\mathrm{MgCl}_{2}, 100 \mu \mathrm{M} \mathrm{MnCl}_{2}, 10 \%$ (w/v) glycerol, $0.1 \mathrm{mg} \mathrm{BSA} \mathrm{ml}{ }^{-1}$ ]. To this solution, the $B$. multivorans Fur protein was added at a final concentration ranging from 0 to $1600 \mathrm{nM}$. After incubation at $30{ }^{\circ} \mathrm{C}$ for $30 \mathrm{~min}$, the reaction mixture was loaded into a $5 \%(\mathrm{w} / \mathrm{v})$ nondenaturing polyacrylamide gel in TBE buffer. After electrophoresis for $1 \mathrm{~h}$ at $100 \mathrm{~V}$, the gel was dried and exposed to an imaging plate, and the gel image was analysed by a FLAS-T1500 system (Fujifilm).

Sequence analysis. The entire genomic sequence of $B$. multivorans ATCC 17616 has been determined (Y. Ohtsubo \& others, unpublished). Detailed analysis of nucleotide sequences for this paper was done by using the GENETYX-MAC program version 13 (Genetyx). The BLAST programs (www.ncbi.nlm.nih.gov/BLAST/) were used for the analysis of sequence homology. A consensus sequence logo was generated using the WEBLOGO program (http:// weblogo.berkeley.edu/).

\section{RESULTS}

\section{Isolation and characterization of the fur gene of B. multivorans ATCC 17616}

We have previously obtained approximately 5,100 derivatives of strain ATCC 17616 by random mutagenesis using a Tn5-based transposon, TnMod-RTp' (Komatsu et al., 2003). The mutant library was screened for the constitutive production of siderophores on CAS agar plates. An orange halo around the colony of one mutant, BT163, was much larger than that of the wild-type strain (Fig. 1a). The addition of $30 \mu \mathrm{M} \mathrm{FeCl}_{3}$ to the CAS agar plates resulted in a decrease in halo size for the wild-type strain, but no change for BT163. This suggested that strain ATCC 17616 represses the production of siderophores under iron-rich conditions and that BT163 constitutively produces an excess of siderophores. Cloning and subsequent analysis of the TnMod-RTp'-flanking genomic region of BT163 revealed that the transposon was inserted into an ORF whose product was identical to the Fur protein of Burkholderia cenocepacia 715j (Lowe et al., 2001). We concluded that the mutated ORF in BT163 is the fur gene since (i) the wild-type phenotype on the CAS agar plate was restored by the introduction into BT163 of pCF1 which carries the wild-type allele of this ORF (Fig. 1a), (ii) the order of the genes flanking this ORF is conserved in other Burkholderia species (Lowe et al., 2001), i.e. omlA (the gene for outer-membrane lipoprotein)-fur-allA (the gene for ureidoglycolate hydrolase), and (iii) no other genes homologous to the fur gene are found in the strain ATCC 17616 genome. (a)

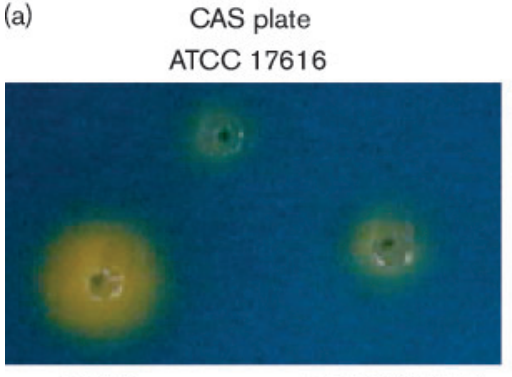

BT163

BT163(PCF1)

(b)

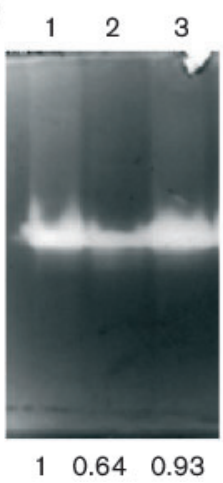

$\mathrm{CAS}$ plate $+\mathrm{FeCl}_{3}$ ATCC 17616

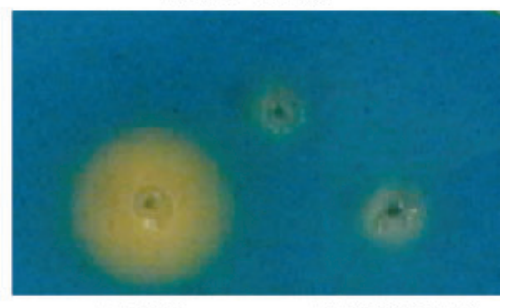

BT163

BT163(PCF1)

(c)

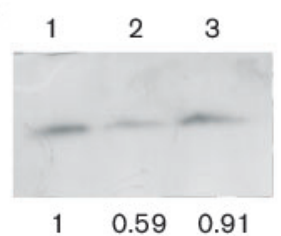

Fig. 1. Characterization of the fur mutation of B. multivorans ATCC 17616. (a) Siderophore production by strains ATCC 17616, BT163 (fur::TnMod-RTp'), and BT163 carrying pCF1 (pME6041::fur) on CAS agar plates with or without $30 \mu \mathrm{M} \mathrm{FeCl}$. (b) and (c) Staining of SOD and catalase activities, respectively. 1, ATCC 17616; 2, DF1 (fur deletion mutant); 3, DF1 carrying pCF1. The supernatant containing a total of $75 \mu \mathrm{g}$ protein was added into each well for electrophoresis. The value below each lane indicates the relative signal intensity of activity staining, taking that of strain ATCC 17616 as 1. 
The transposon insert in the BT163 genome was between the 69th and 70th base positions in the 426-base fur gene. This insert led to the formation of a putative fusion ORF whose 3 ' portion encoded the C-terminal 119 amino acid residues of the Fur protein. It was theoretically possible that this presumptive fusion protein still had the ability to exert certain residual functions of Fur. Our attempt to completely remove the fur gene from strain ATCC 17616 genome led to successful generation of strain DF1, and its phenotype on the CAS agar plate was the same as that of strain BT163 (data not shown). Thereafter in this study, we used strain DF1 as a fur deletion mutant.

\section{Sensitivity of the fur deletion mutant to ROS and nitrogen compounds}

Disk assays showed that strain DF1 cells were more sensitive to $\mathrm{H}_{2} \mathrm{O}_{2}$ and paraquat than strain ATCC 17616 cells (data not shown). Crude cell extracts prepared from strains ATCC 17616 and DF1 were subjected to native PAGE and subsequent activity staining (Fig. 1b). A single band for SOD activity was detected from both strains, and the enzymic activity of this band from strain DF1 was 1.6fold lower than that from strain ATCC 17616. Only one gene for cytoplasmic iron-containing SOD, $\operatorname{sodB}$, was found in the ATCC 17616 genome. Northern analysis revealed that the amount of $\operatorname{sodB}$ mRNA was 1.6-fold lower in strain DF1 than in strain ATCC 17616 (data not shown). The catalase activity was also 1.7 -fold lower in strain DF1 (Fig. 1c). Both activities were restored by the introduction of pCF1 into strain DF1 (Fig. 1b, c). These results indicated that the ATCC 17616 Fur protein is involved in the production of enzymes for removal of ROS.

To determine the involvement of Fur in the metabolism of inorganic nitrogen compounds, i.e. nitrate, nitrite and NO, the growth of ATCC 17616 and DF1 cells was investigated using EB broth or EB agar plates supplemented with one of the three inorganic nitrogen compounds. The sensitivity of strains ATCC 17616 and DF1 to nitrate was unchanged under aerobic and anaerobic conditions (data not shown). The sensitivity to nitrite under aerobic conditions was slightly higher for strain DF1 than for ATCC 17616 (Fig. 2a). However, strain DF1 was remarkably sensitive to nitrite under microanaerobic conditions (i.e. there was a $10^{4}$-fold decrease in the number of c.f.u. in comparison with ATCC 17616) (Fig. 2a). The sensitivity of strain DF1 was restored to that of ATCC 17616 by the introduction of pCF1. We investigated the aerobic growth of ATCC 17616 and DF1 cells in EB broth with and without the addition of acidified nitrite (Fig. 2b). Strain DF1 in EB broth grew slightly slower than ATCC 17616. The addition of acidified nitrite led to profound growth defects of both strains, but the defect in DF1 cells was much more severe than that in ATCC 17616 cells. These results indicate that Fur is necessary for the adaptation to nitrosative stress.

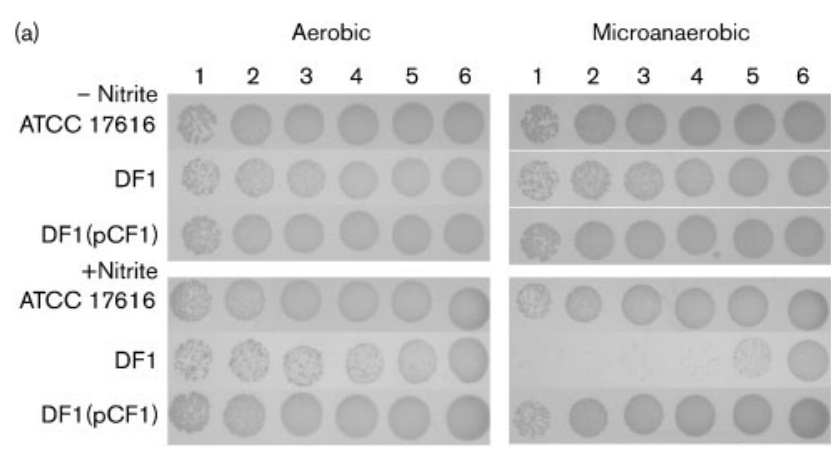

(b)

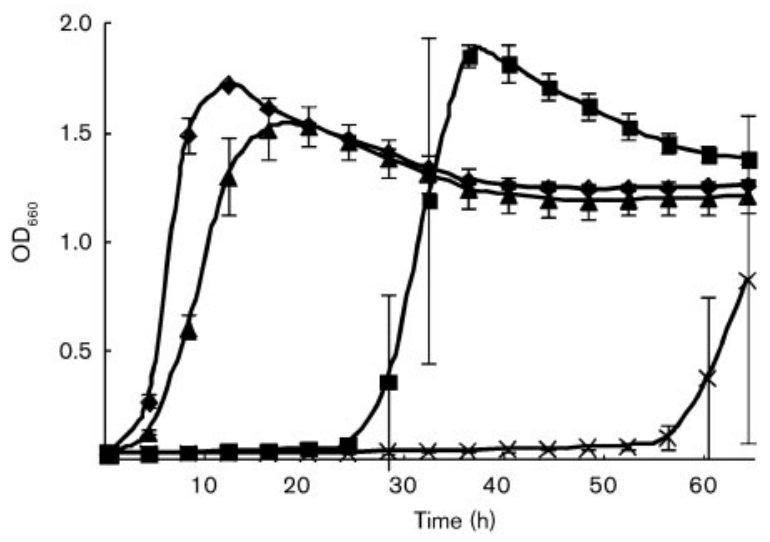

Fig. 2. Assay of sensitivity to nitrogen compounds. (a) Sensitivity of strain ATCC 17616 and DF1 cells to nitrite under aerobic and microaerobic conditions was measured by the number of c.f.u. on EB agar plates with or without $5 \mathrm{mM}$ sodium nitrite. Columns 1-6 indicate the various dilutions of late-exponential-phase cells from $5 \times 10^{3}$ to $5 \times 10^{8}$ c.f.u. $\mathrm{ml}^{-1}$ in tenfold steps, respectively (see Methods). (b) Sensitivity to NO under aerobic conditions was analysed by measuring the $\mathrm{OD}_{660}$ of cultures in $\mathrm{EB}$ at $30{ }^{\circ} \mathrm{C}$ with or without $2 \mathrm{mM}$ acidified nitrite (see Methods). Error bars represent the SD from at least three independent experiments. $\checkmark$ ATCC 17616; $\boldsymbol{\square}$, ATCC 17616 + acidified nitrate; $\boldsymbol{\Delta}$, DF1; $\times$, DF1 + acidified nitrate.

\section{Carbon assimilation of strain ATCC 17616 and its fur deletion mutant}

We also examined the effect of the fur mutation on the ability of cells to grow on M9 minimal agar containing any of 33 carbon sources that are available to the wild-type strain (14 sugar compounds, 12 organic acids and 7 aromatic compounds listed in Table 2). When ascorbate, gentisate and anthranilate were employed as carbon sources, the number of c.f.u. of DF1 cells was slightly lower (10- to 100-fold) than those of ATCC 17616 cells. Use of any of the remaining compounds resulted in a severe decrease in the number of c.f.u. of DF1 cells, but not ATCC 17616 cells, and these defects in strain DF1 were most remarkable with fructose, ribose, dulcitol, mannose and tartrate as carbon source. These growth defects in strain DF1 were complemented by the introduction of pCF1. In contrast to the growth-based assay, employment of Biolog GN2, a cellular respiration assay system, revealed 
that the fur mutation caused reduced cellular respiration activities only when adonitol, arabinose, lactose, ketovalerate, leucine and carnitine were used as the substrates. However, cellular respiration of strain DF1 was still observed even when the substrate was any one of the 13 carbon compounds (fructose, galactose, glucose, inositol, mannitol, mannose, sorbitol, trehalose, acetate, citrate, malonate, succinate and ornithine) that produced a growth defect in strain DF1 (Table 2). These results suggest that although the fur mutation causes severe defects in the ability of the cell to use various carbon sources, these are not ascribable to the oxidative respiration of these carbon sources.

\section{Analysis of Fur-binding regions of the ATCC 17616 genome}

The E. coli strain H1780 is a fur deletion mutant, and carries a fusion of the fiu promoter and promoterless lac $Z$ gene, the expression of which is repressed by Fur under iron-rich conditions (Hantke, 1987). Plasmid pEF1 carries the fur gene from B. multivorans ATCC 17616 ( fur $_{\mathrm{Bm}}$ ). Introduction of this plasmid into H1780 resulted in a drastic decrease in $\beta$-galactosidase activity under iron-rich but not iron-limiting conditions (data not shown), indicating that fur $_{\mathrm{Bm}}$ shares at least some functional exchangeability with the E. coli fur gene $\left(f u r_{\mathrm{EC}}\right)$. Based on this result, the FURTA system (Stojiljkovic et al., 1994) was used to isolate the ATCC 17616 DNA sequences to which the Fur $_{\mathrm{Ec}}$ protein is able to bind with high affinity. In this assay, an E. coli fur ${ }^{+}$strain (H1717) was used that carries a chromosomal copy of the Fur-repressed promoter ( fhuF promoter) connected to a promoterless lacZ gene (Hantke, 1987). The introduction of a multicopy plasmid carrying a Fur-binding sequence (Fur box) into H1717 leads to the titration of Fur by the plasmid-specified Fur box, thus allowing the transcription of the fused lac $Z$ gene.

The introduction of a pHSG398-based genomic library of ATCC 17616 into H1717 and screening of $9 \times 10^{4}$ clones on a MacConkey lactose agar plate containing $30 \mu \mathrm{M} \mathrm{FeCl}_{3}$ gave rise to $115 \mathrm{LacZ}^{+}$colonies. Subsequent sequence analysis of plasmids in these $\mathrm{LacZ}^{+}$colonies revealed that 13 regions carried putative Fur-binding sequences (Table 3 ). All of these sequences were located within or very close to the putative promoter sequences, nine of which were followed by genes postulated to encode proteins for iron acquisition or cellular iron homeostasis (regions 2-7 and 10-12 in Table 3). Four such proteins encoded by regions 2, 6, 10 and 11 were putative TonB-dependent outermembrane receptor proteins for siderophores of unknown origins, but their genes were not flanked by genes related to iron acquisition. In contrast, regions 3 and 12 apparently encode all the components necessary for the ABC-type ferric ion transporter system and TonB-dependent haemin uptake system, respectively (Fig. 3a and supplementary Table S2, available with the online version of this paper). Two genes (fecI and orbS in regions 4 and 5, respectively)
Table 2. Carbon assimilation of strains ATCC 17616 and DF1

The c.f.u. of strains ATCC 17616 and DF1 on EB and M9 agar plates containing one carbon source was measured as described in Methods. For simplicity, the following symbols are arbitrarily employed to indicate the relative c.f.u., taking that of strain ATCC 17616 on an EB plate as $1:+++$, between 1 and $10^{-1}$; ++ , between $9 \times 10^{-2}$ and $10^{-3}$; + , between $9 \times 10^{-4}$ and $10^{-5} ;-$, less than $9 \times 10^{-6}$.

\begin{tabular}{|c|c|c|}
\hline \multirow[t]{2}{*}{ Carbon source } & \multicolumn{2}{|c|}{ Strain } \\
\hline & ATCC 17616 & DF1 \\
\hline \multicolumn{3}{|l|}{ Sugars } \\
\hline Glucose & +++ & + \\
\hline Fructose & +++ & + \\
\hline Ribose & +++ & + \\
\hline Mannose & +++ & + \\
\hline Xylose & +++ & + \\
\hline Trehalose & +++ & + \\
\hline Galactose & +++ & + \\
\hline Arabinose & +++ & ++ \\
\hline Cellobiose & +++ & + \\
\hline Inositol & +++ & + \\
\hline Sorbitol & +++ & + \\
\hline Ribitol & +++ & + \\
\hline Mannitol & +++ & + \\
\hline Dulcitol & +++ & + \\
\hline \multicolumn{3}{|l|}{ Organic acids } \\
\hline Pyruvate & +++ & ++ \\
\hline Succinate & +++ & + \\
\hline Isocitrate & +++ & ++ \\
\hline Citrate & +++ & + \\
\hline Fumarate & +++ & ++ \\
\hline Tartrate & +++ & + \\
\hline Acetate & +++ & + \\
\hline Malonate & +++ & + \\
\hline Ascorbate & + & - \\
\hline Ornithine & +++ & + \\
\hline Shikimate & +++ & ++ \\
\hline Glycerophosphate & +++ & + \\
\hline \multicolumn{3}{|l|}{ Aromatic acids } \\
\hline Salicylate & + & - \\
\hline Gentisate & + & - \\
\hline Hydroxyphenylpyruvate & +++ & ++ \\
\hline Hydroxybenzoate & +++ & ++ \\
\hline Benzoate & ++ & + \\
\hline Anthranilate & + & + \\
\hline Phthalate & +++ & + \\
\hline EB & +++ & +++ \\
\hline
\end{tabular}

were found that putatively encode extracytoplasmic function (ECF) sigma factors for iron acquisition (ironstarvation sigma factors). It is well known that (i) the transcription of genes for ferric-citrate transport in E. coli requires FecI, and (ii) FecR, a cytoplasmic membrane protein encoded by the second gene in the Fur-repressed fecIR operon which transmits an external iron signal to the cytoplasmic FecI protein (Braun et al., 2003). 
Table 3. Regions containing Fur-regulated genes of strain ATCC 17616

\begin{tabular}{|c|c|c|c|c|c|c|c|c|c|c|c|}
\hline \multirow[t]{2}{*}{ Region } & \multicolumn{6}{|c|}{ First gene just downstream of Fur box } & \multicolumn{4}{|c|}{ Putative Fur box } & \multirow{2}{*}{$\begin{array}{l}\text { Ratio of transcription } \\
\text { of the first gene (DF1/ } \\
\text { ATCC 17616)\| }\end{array}$} \\
\hline & Chr & From & To & Direction & $\begin{array}{l}\text { Gene } \\
\text { name }\end{array}$ & Putative function or product $^{*}$ & Fur-box element $\dagger$ & $\begin{array}{l}\text { Match to } \\
\text { E. coli Fur } \\
\text { box }\end{array}$ & $\begin{array}{l}\text { Palindrome } \\
\quad \text { length } \ddagger\end{array}$ & $\begin{array}{l}\text { Distance } \\
\text { from trans- } \\
\text { lational start } \$\end{array}$ & \\
\hline 1 & I & 185075 & 185809 & + & & $\begin{array}{l}\text { Conserved hypothetical protein } \\
\text { (Burkholderia sp. } 383,198 / 225,88 \% \text { ) }\end{array}$ & tgTAATGATAgcCATTcTC & 14 & 4 & 88 & $50.1 \pm 13.2$ \\
\hline 2 & I & 300436 & 302637 & + & & $\begin{array}{l}\text { TonB-dependent outer-membrane } \\
\text { siderophore receptor (Burkholderia } \\
\text { ambifaria MC40-6, 605/733, 82\%) }\end{array}$ & tggAATGAgAAcCATTcTC & 13 & 5 & 40 & $11.2 \pm 5.08$ \\
\hline 3 & I & 1225998 & 1227041 & - & & $\begin{array}{l}\text { Substrate-binding protein of ABC-type } \\
\mathrm{Fe}^{3+} \text { transporter system (Burkholderia } \\
\text { ambifaria MC40-6, 330/347, } 95 \%)\end{array}$ & GATAATcATtccCATTtcg & 12 & 3 & 119 & $92.2 \pm 28.1$ \\
\hline 4 & I & 1401255 & 1401764 & + & fecI & $\begin{array}{l}\text { ECF subfamily RNA polymerase sigma } \\
\text { factor (Burkholderia sp. } 383,156 / 169 \\
(92 \%)\end{array}$ & GtatATaATAATCATTcTC & 14 & 5 & 58 & $58.7 \pm 13.9$ \\
\hline 5 & I & 1748437 & 1749078 & + & orbs & $\begin{array}{l}\text { ECF subfamily RNA polymerase } \\
\text { sigma factor (Burkholderia cenocepacia, } \\
190 / 220,86 \% \text { ) }\end{array}$ & GAgAATGATttgCgTTtaC & 12 & 4 & 64 & $2.24 \times 10^{3} \pm 0.63 \times 10^{3}$ \\
\hline 7 & I & 2346617 & 2346853 & + & $b f d$ & $\begin{array}{l}\text { Bacterioferritin-associated ferredoxin } \\
\text { (Burkholderia cenocepacia AU 1054, } \\
75 / 78,96 \% \text { ) }\end{array}$ & ttTAATGATAATaATTcgC & 14 & 5 & 44 & $332 \pm 88.8$ \\
\hline 8 & I & 2352051 & 2352296 & + & & $\begin{array}{l}\text { Conserved hypothetical protein } \\
\text { (Burkholderia dolosa AUO158, } \\
74 / 81,91 \%)\end{array}$ & GtaAATGggAATagTTATC & 13 & 3 & 64 & $878 \pm 167$ \\
\hline 9 & I & 3349867 & 3351105 & - & & $\begin{array}{l}\text { Uncharacterized iron-regulated } \\
\text { membrane protein (Burkholderia } \\
\text { dolosa AUO158, 356/412, } 86 \% \text { ) }\end{array}$ & tAgAATGtcgcgCgTTgTC & 10 & 4 & 185 & $9.30 \pm 2.39$ \\
\hline 10 & II & 1697287 & 1699533 & + & & $\begin{array}{l}\text { TonB-dependent outer-membrane } \\
\text { siderophore receptor (Burkholderia } \\
\text { cepacia AMMD, 692/748, 92\%) }\end{array}$ & agaAATcgTAATaATTccC & 11 & 4 & 81 & $560 \pm 202$ \\
\hline 11 & II & 1958624 & 1960828 & - & & $\begin{array}{l}\text { TonB-dependent outer-membrane } \\
\text { siderophore receptor (Burkholderia } \\
\text { ambifaria MC40-6, 656/684, 95\%) }\end{array}$ & GATAccGATtcTCATTtgC & 13 & 4 & 179 & $7.90 \pm 5.93$ \\
\hline
\end{tabular}




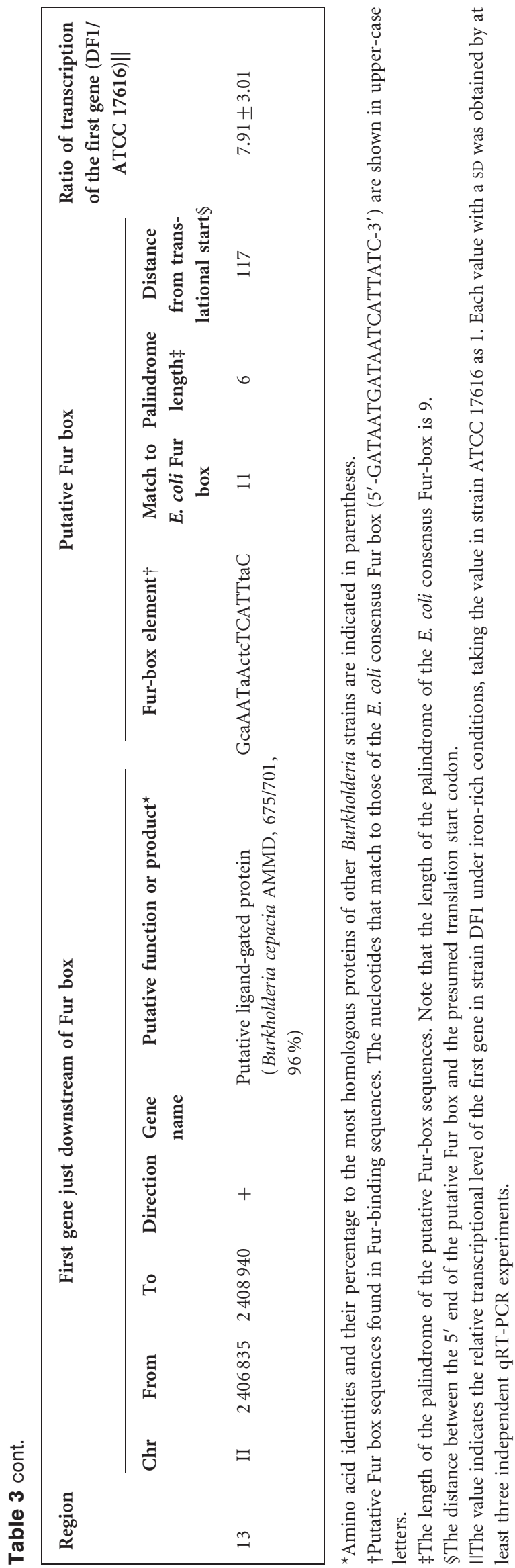

In B. multivorans ATCC 17616, the fecI gene is followed by fecR (Fig. 3a and supplementary Table S2). We constructed a knockout mutant of the strain ATCC 17616 fecI gene, but its subsequent analysis using iron-limiting and the CAS plates revealed no apparent effects of the mutation on iron acquisition (data not shown). The orbS gene in strain ATCC 17616 is followed by the genes encoding the biosynthesis of an ornibactin-like siderophore of unknown structure (Fig. 3a and supplementary Table S2). The involvement of these genes in the biosynthesis was confirmed by our observation in which the TnMod-RTp' insertion mutant in orbI did not support its growth on iron-limiting agar, nor form the orange halo zone on the CAS plate (data not shown). The same phenotypes were also observed for the ATCC 17616 orbS mutant (data not shown), supporting the idea that this gene product is required for the biosynthesis of a siderophore. The putative Fur-binding sequence in region 7 is followed by bfd that putatively encodes bacterioferritin (Bfr)-associated ferredoxin (Fig. 3a and supplementary Table S2), and is considered to act as a Bfr reductase, mediating the release of iron from this iron storage protein (Andrews et al., 2003). Downstream of the bfd gene is the tonB-exbB-exbD cluster which encodes, in other bacteria, a system to transduce cellular energy to outer-membrane receptors for siderophores and haemin (Schalk et al., 2004).

To confirm that the Fur ${ }_{B m}$ protein was indeed capable of binding to the putative Fur box-like sequences obtained above, this protein was purified as described in Methods. EMSA analysis confirmed that the purified $\mathrm{Fur}_{\mathrm{Bm}}$ protein binds to all 13 putative Fur box-like sequences (Fig. 3 and data not shown). The predicted Fur-binding sequences obtained by FURTA were used to generate a consensus logo sequence (Fig. 4). This logo sequence indicates that the AAT (residues 4-6) and ATT (residues 14-16) motifs are well conserved and form palindromic sequences. These sequences are also conserved in the Fur box of E. coli, strongly suggesting that $\operatorname{Fur}_{\mathrm{Bm}}$ and $\mathrm{Fur}_{\mathrm{Ec}}$ recognize these common sequences. qRT-PCR was carried out to investigate transcription of the genes located just downstream of the Fur boxes in strains ATCC 17616 and DF1 (Table 3) under iron-rich conditions. All of these genes in strain DF1 were transcribed at levels 7.9- to 4900-fold higher than those in ATCC 17616. These results clearly indicate that the Fur $_{\mathrm{Bm}}$ protein acts as a repressor for expression of these genes in strain ATCC 17616.

\section{DISCUSSION}

In this study we isolated an insertion mutant of the ATCC 17616 fur gene, and demonstrated that its deletion mutant is viable under conventional cultivation conditions. This dispensability of Fur in ATCC 17616 contrasts with the essentiality of the fur gene in B. pseudomallei (Loprasert et al., 2000), and this is the first report of a successful construction of a fur deletion mutation in a Burkholderia species. Null mutations of fur can be isolated in E. coli and 
(a)

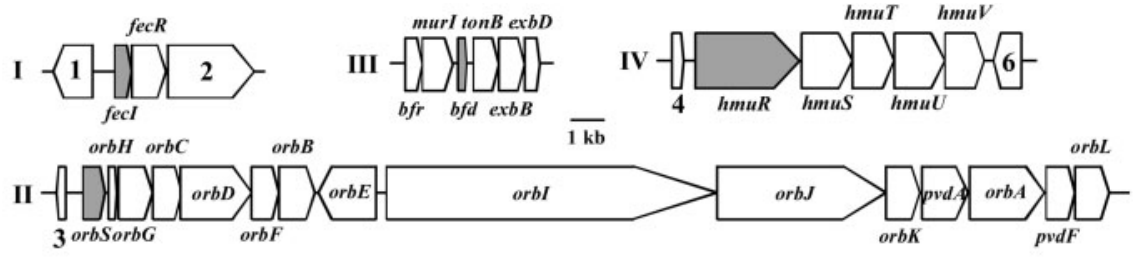

(b)

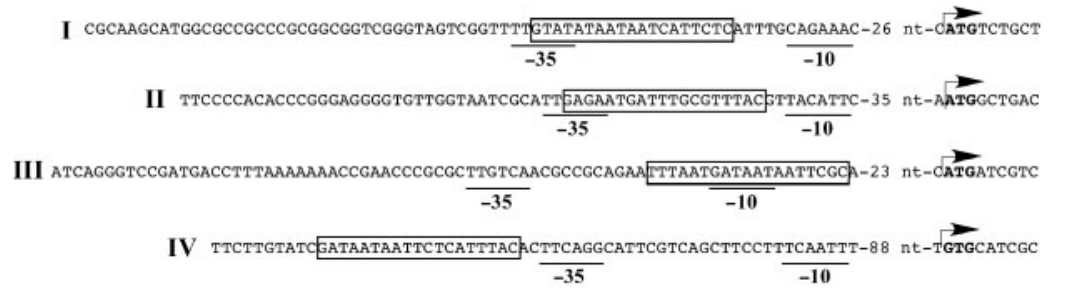

(c) I

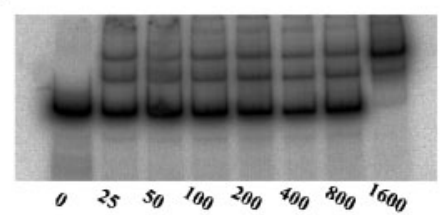

III

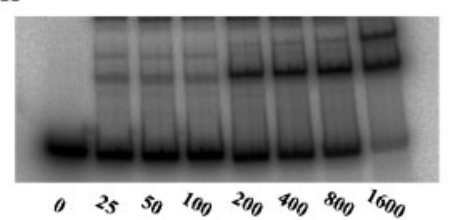

II

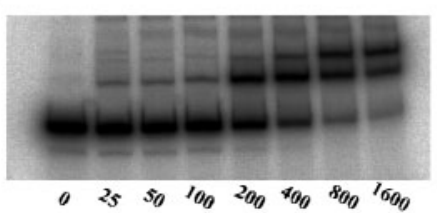

IV

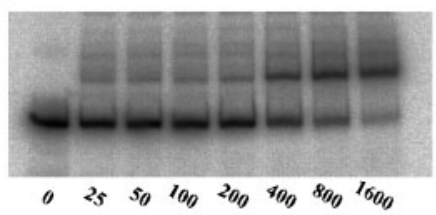

Fig. 3. Fur-regulated gene clusters of B. multivorans ATCC 17616. I, II, III, and IV correspond to regions 4, 5, 7, and 12 described in Table 3. (a) Genetic maps of the Fur box-containing regions. The genes located just downstream of the Fur boxes are shown in grey. A detailed description of the genes is given in supplementary Table S2. (b) Relative position of Fur box (open box) to the -10 and -35 sequences of the putative promoter and the putative start codon (bold type). The arrow indicates the direction of transcription. (c) EMSA analysis for the binding of Fur $_{\mathrm{Bm}}$ to the Fur box-containing sequence. The concentration of $\operatorname{Fur}_{\mathrm{Bm}}(\mathrm{nM})$ used for the analysis is listed at the bottom of each lane.

Neisseria species, but not, for example, in $P$. aeruginosa (Vasil, 2007). It is still unknown why Fur is essential for some bacterial strains but not for other related strains. A detailed comparison of iron- and Fur-regulated genes in the two Burkholderia genomes might clarify the reason(s) for this difference.

Our results strongly suggest that Fur is necessary to adapt to nitrosative stress in strain ATCC 17616. The involve-

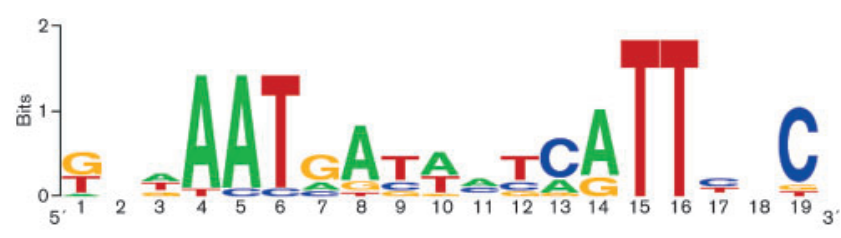

Fig. 4. Sequence logo of the Fur box of B. multivorans ATCC 17616. The Fur boxes listed in Table 3 were used to determine the consensus nucleotide frequencies by using the WEBLOGO program. ment of Fur in nitrogen metabolism has been reported in other bacteria. The Fur protein in Neisseria meningitidis activates the pan 1 and nor $B$ genes, which encode nitrite and NO reductases, respectively (Delany et al., 2004), and the E. coli fur mutant exhibits a severe growth delay under aerobic conditions in the presence of nitrosylated glutathione or acidified nitrite (Mukhopadhyay et al., 2004). In contrast, we showed in this study that the fur mutation in strain ATCC 17616 causes hypersensitivity to nitrite under microaerobic conditions and also acidified nitrite (an NO producer) under aerobic conditions. Nitrite and $\mathrm{NO}$ are reactive nitrogen species that induce bacterial damage through interaction with DNA and proteins containing iron/zinc-sulfur clusters, haem, thiols, tyrosyl radicals, tyrosine residues or amines (Lundberg et al., 2004). Cells of strain DF1 might fail to remove nitrite and/or NO, thereby resulting in high sensitivities to these compounds.

As has been observed in other bacterial strains, the fur mutant of ATCC 17616 was more sensitive to ROS than the wild-type strain, and the enzymic activities of SodB and 
catalase for the removal of ROS were reduced. Our observation that the amount of $\operatorname{sodB}$ mRNA in DF1 cells was slightly lower than that in ATCC 17616 cells suggests that Fur directly or indirectly activates the transcription of $\operatorname{sodB}$. Fur binds directly to the $\operatorname{sodB}$ promoter to activate $\operatorname{sodB}$ transcription in $N$. meningitidis (Sebastian et al., 2002). In contrast, small regulatory RNA molecules (sRNAs) are involved in inhibiting translation of the $\operatorname{sodB}$ gene in E. coli and P. aeruginosa (Masse \& Gottesman, 2002; Wilderman et al., 2004). In these bacteria, the active form of Fur under iron-rich conditions binds Fur boxes that are located upstream of sRNAs thus repressing their transcription and allowing the translation of $\operatorname{sodB}$ mRNA. Since no Fur-box like sequences were found at the region upstream of the strain ATCC $17616 \operatorname{sodB}$ gene, it is most likely that the Fur protein indirectly activates the expression of $\operatorname{sod} B$.

The fur mutant of ATCC 17616 showed, when compared to the wild-type strain, a reduced ability to assimilate various carbon sources (Table 2). The fur mutation in E. coli causes a loss of the ability to use non-fermentable carbon sources such as succinate, acetate and fumarate (Andrews et al., 2003; Hantke, 1987). However, strain ATCC 17616 was unique in that its fur mutant could not efficiently assimilate either fermentable or non-fermentable carbon sources. Another unique property revealed by the carbon assimilation tests was that many compounds that could not be readily employed as carbon sources in the fur mutant were still available as substrates for cellular respiration. This implies that the growth defect of the mutant was not primarily due to defect(s) in its respiration. Our preliminary results indicated that the growth defect of DF1 cells on an M9 glucose agar plate was in part suppressed under iron-limiting and microaerobic conditions (data not shown). Since large amounts of ROS (e.g. $\mathrm{H}_{2} \mathrm{O}_{2}$ and hydroxy radical) are produced by the Fenton reaction in cells grown under iron-rich and aerobic conditions (Andrews et al., 2003), the growth defect of DF1 on M9 glucose agar might be due to the accumulation of ROS. The Fur proteins in E. coli and P. aeruginosa apparently activate the genes for succinate dehydrogenase under ironrich conditions through the transcriptional repression of antisense sRNAs against these dehydrogenase genes (Masse \& Gottesman, 2002; Mellin et al., 2007; Vasil, 2007; Wilderman et al., 2004). It would be of interest to know whether a similar mechanism is involved in the expression of such dehydrogenase genes in B. multivorans ATCC 17616.

Many Gram-negative bacterial species have the ability to use various kinds of exogenous siderophores that they do not produce themselves, and these abilities depend on the expression of genes encoding outer-membrane receptors specific to the exogenous siderophores (Andrews et al., 2003). B. multivorans ATCC 17616 may also have such abilities because four Fur-repressive genes encoding putative siderophore receptors were identified in regions 2, 6, 10 and 11 (Table 3). However, it is uncertain whether these genes have the expected functions, since they are not similar to other genes clearly involved in iron acquisition. Another putative siderophore receptor gene, orbA, in region 5 is expected to be functional because it is located within the biosynthetic gene cluster for an ornibactin-like siderophore, and orbI in this cluster is required for the production of this siderophore (Table 3, Fig. 3a and supplementary Table S2). However, no Fur boxes are found at the positions upstream of orbA and other genes, with the exception of orbS. Therefore, it is most plausible that (i) the transcription of siderophore biosynthetic genes and $\operatorname{orb} A$ requires the orbS product as an ECF sigma factor, and (ii) orbS transcription is repressed under iron-rich conditions by the active form of Fur. Such a two-step regulation process has been demonstrated in the ornibactin biosynthetic genes in B. cenocepacia 715j (Agnoli et al., 2006). orbS is an orthologue of $p v d S$ (an ECF sigma factor gene for pyoverdine synthesis) from $P$. aeruginosa, and PvdS is essential for the production of various virulence factors (Beare et al., 2003; Lamont et al., 2002; Visca et al., 2002). It would be of interest to examine whether OrbS in B. multivorans ATCC 17616 also plays pleiotropic roles in the production of various proteins.

Tuanyok et al. (2005) have carried out transcriptome analyses of Burkholderia mallei and B. pseudomallei under iron-rich and iron-limiting conditions, and the transcriptional levels of more than 200 genes in each species were reported to be drastically changed, depending on the iron concentration. Many homologues of Fur-regulated ATCC 17616 genes identified in our current study are listed in the data of Tuanyok et al. (2005) and one of these genes is $b f d$. However, there has been no further detailed analysis of this gene. In contrast, our study clearly demonstrates that the transcription of the bfd gene in ATCC 17616 is directly repressed by Fur, and such definitive experimental data have not been obtained even in E. coli (Andrews et al., 2003).

Since the genome sequence of B. multivorans ATCC 17616 has been determined (Y. Ohtsubo \& others, unpublished), use of this strain and its fur and orbS mutants for transcriptome and subsequent qRT-PCR analyses will clarify (i) the direct and indirect target genes of these two regulator products and (ii) how the extracellular iron signal is transmitted to each member of the Fur regulon.

\section{ACKNOWLEDGEMENTS}

This work was supported by Grant-in-Aids from the Ministry of Education, Culture, Sports, Science and Technology, and the Ministry of Agriculture, Forestry and Fisheries (HC-06-2323), Japan.

\section{REFERENCES}

Abdul-Tehrani, H., Hudson, A. J., Chang, Y. S., Timms, A. R., Hawkins, C., Williams, J. M., Harrison, P. M., Guest, J. R. \& Andrews, S. C. (1999). Ferritin mutants of Escherichia coli are iron deficient and 
growth impaired, and fur mutants are iron deficient. J Bacteriol 181, 1415-1428.

Agnoli, K., Lowe, C. A., Farmer, K. L., Husnain, S. I. \& Thomas, M. S. (2006). The ornibactin biosynthesis and transport genes of Burkholderia cenocepacia are regulated by an extracytoplasmic function sigma factor which is a part of the Fur regulon. J Bacteriol 188, 3631-3644.

Amann, E. \& Brosius, J. (1985). ATG vectors for regulated high-level expression of cloned genes in Escherichia coli. Gene 40, 183-190.

Andrews, S. C., Robinson, A. K. \& Rodriguez-Quinoñes, F. (2003). Bacterial iron homeostasis. FEMS Microbiol Rev 27, 215-237.

Ausubel, F. M., Brent, R., Kingston, E. R., Moore, D. D., Seidman, G. J., Smith, A. J. \& Struhk, K. (1991). Current Protocols in Molecular Biology. New York: John Wiley \& Sons.

Banin, E., Vasil, M. L. \& Greenberg, E. P. (2005). Iron and Pseudomonas aeruginosa biofilm formation. Proc Natl Acad Sci U S A 102, 11076-11081.

Beare, P. A., For, R. J., Martin, L. W. \& Lamont, I. L. (2003). Siderophore-mediated cell signalling in Pseudomonas aeruginosa: divergent pathways regulate virulence factor production and siderophore receptor synthesis. Mol Microbiol 47, 195-207.

Braun, V., Mahren, S. \& Ogierman, M. (2003). Regulation of the FecItype ECF sigma factor by transmembrane signalling. Curr Opin Microbiol 6, 173-180.

Chang, A. C. \& Cohen, S. N. (1978). Construction and characterization of amplifiable multicopy DNA cloning vehicles derived from the P15A cryptic miniplasmid. J Bacteriol 134, 1141-1156.

Cheng, H. P. \& Lessie, T. G. (1994). Multiple replicons constituting the genome of Pseudomonas cepacia 17616. J Bacteriol 176, 40344042.

Chiarini, L., Bevivino, A., Dalmastri, C., Tabacchioni, S. \& Visca, P. (2006). Burkholderia cepacia complex species: health hazards and biotechnological potential. Trends Microbiol 14, 277-286.

Delany, I., Rappuoli, R. \& Scarlato, V. (2004). Fur functions as an activator and as a repressor of putative virulence genes in Neisseria meningitidis. Mol Microbiol 52, 1081-1090.

Dennis, J. J. \& Zylstra, G. J. (1998). Plasposons: modular self-cloning minitransposon derivatives for rapid genetic analysis of Gramnegative bacterial genomes. Appl Environ Microbiol 64, 2710-2715.

Escolar, L., Perez-Martin, J. \& de Lorenzo, V. (1999). Opening the iron box: transcriptional metalloregulation by the Fur protein. J Bacteriol 181, 6223-6229.

Hall, H. K. \& Foster, J. W. (1996). The role of fur in the acid tolerance response of Salmonella typhimurium is physiologically and genetically separable from its role in iron acquisition. J Bacteriol 178, 5683-5691.

Hantke, K. (1987). Selection procedure for deregulated iron transport mutants (fur) in Escherichia coli K 12: fur not only affects iron metabolism. Mol Gen Genet 210, 135-139.

Heeb, S., Itoh, Y., Nishijyo, T., Schnider, U., Keel, C., Wade, J., Walsh, U., O'Gara, F. \& Haas, D. (2000). Small, stable shuttle vectors based on the minimal pVS1 replicon for use in Gram-negative, plant-associated bacteria. Mol Plant Microbe Interact 13, 232-237.

Hoang, T. T., Karkhoff-Schweizer, R. R., Kutchma, A. J. \& Schweizer, H. P. (1998). A broad-host-range Flp-FRT recombination system for site-specific excision of chromosomally-located DNA sequences: application for isolation of unmarked Pseudomonas aeruginosa mutants. Gene 212, 77-86.

Komatsu, H., Imura, Y., Ohori, A., Nagata, Y. \& Tsuda, M. (2003). Distribution and organization of auxotrophic genes on the multichromosomal genome of Burkholderia multivorans ATCC 17616. J Bacteriol 185, 3333-3343.
Lamont, I. L., Beare, P. A., Ochsner, U., Vasil, A. I. \& Vasil, M. L. (2002). Siderophore-mediated signaling regulates virulence factor production in Pseudomonas aeruginosa. Proc Natl Acad Sci U S A 99, 7072-7077.

Lefebre, M. \& Valvano, M. (2001). In vitro resistance of Burkholderia cepacia complex isolates to reactive oxygen species in relation to catalase and superoxide dismutase production. Microbiology 147, 97-109.

Lessie, T. G., Hendrickson, W., Manning, B. D. \& Devereux, R. (1996). Genomic complexity and plasticity of Burkholderia cepacia. FEMS Microbiol Lett 144, 117-128.

Litwin, C. M. \& Calderwood, S. B. (1993). Role of iron in regulation of virulence genes. Clin Microbiol Rev 6, 137-149.

Loprasert, S., Sallabhan, R., Whangsuk, W. \& Mongkolsuk, S. (2000). Characterization and mutagenesis of fur gene from Burkholderia pseudomallei. Gene 254, 129-137.

Lowe, C. A., Asghar, A. H., Shalom, G., Shaw, J. G. \& Thomas, M. S. (2001). The Burkholderia cepacia fur gene: co-localization with omlA and absence of regulation by iron. Microbiology 147, 1303-1314.

Lundberg, J. O., Weitzberg, E., Cole, J. A. \& Benjamin, N. (2004). Nitrate, bacteria and human health. Nat Rev Microbiol 2, 593-602.

Mahenthiralingam, E., Urban, T. A. \& Goldberg, J. B. (2005). The multifarious, multireplicon Burkholderia cepacia complex. Nat Rev Microbiol 3, 144-156.

Masse, E. \& Gottesman, S. (2002). A small RNA regulates the expression of genes involved in iron metabolism in Escherichia coli. Proc Natl Acad Sci U S A 99, 4620-4625.

Mellin, J. R., Goswami, S., Grogan, S., Tjaden, B. \& Genco, C. A. (2007). A novel fur- and iron-regulated small RNA, NrrF, is required for indirect fur-mediated regulation of the $s d h A$ and $s d h C$ genes in Neisseria meningitidis. J Bacteriol 189, 3686-3694.

Mey, A. R., Wyckoff, E. E., Kanukurthy, V., Fisher, C. R. \& Payne, S. M. (2005). Iron and fur regulation in Vibrio cholerae and the role of fur in virulence. Infect Immun 73, 8167-8178.

Mukhopadhyay, P., Zheng, M., Bedzyk, L. A., LaRossa, R. A. \& Storz, G. (2004). Prominent roles of the NorR and Fur regulators in the Escherichia coli transcriptional response to reactive nitrogen species. Proc Natl Acad Sci U S A 101, 745-750.

Nagata, Y., Matsuda, M., Komatsu, H., Imura, Y., Sawada, H., Ohtsubo, Y. \& Tsuda, M. (2005). Organization and localization of the $d n a A$ and $d n a K$ gene regions on the multichromosomal genome of Burkholderia multivorans ATCC 17616. J Biosci Bioeng 99, 603-610.

Ohtsubo, Y., Goto, H., Nagata, Y., Kudo, T. \& Tsuda, M. (2006). Identification of a response regulator gene for catabolite control from a PCB-degrading beta-proteobacteria, Acidovorax sp. KKS102. Mol Microbiol 60, 1563-1575.

Parke, J. L. \& Gurian-Sherman, D. (2001). Diversity of the Burkholderia cepacia complex and implications for risk assessment of biological control strains. Annu Rev Phytopathol 39, 225-258.

Qing, G., Ma, L. C., Khorchid, A., Swapna, G. V., Mal, T. K., Takayama, M. M., Xia, B., Phadtare, S., Ke, H. \& other authors (2004). Coldshock induced high-yield protein production in Escherichia coli. Nat Biotechnol 22, 877-882.

Sambrook, J. \& Russell, W. D. (2001). Molecular Cloning: a Laboratory Manual, 3rd edn. Cold Spring Harbor, NY: Cold Spring Harbor Laboratory Press.

Schalk, I. J., Yue, W. W. \& Buchanan, S. K. (2004). Recognition of iron-free siderophores by TonB-dependent iron transporters. Mol Microbiol 54, 14-22.

Schwyn, B. \& Neilands, J. B. (1987). Universal chemical assay for the detection and determination of siderophores. Anal Biochem 160, 4756. 
Sebastian, S., Agarwal, S., Murphy, J. R. \& Genco, C. A. (2002). The gonococcal fur regulon: identification of additional genes involved in major catabolic, recombination, and secretory pathways. J Bacteriol 184, 3965-3974.

Stojiljkovic, I., Bäumler, A. J. \& Hantke, K. (1994). Fur regulon in Gram-negative bacteria. Identification and characterization of new iron-regulated Escherichia coli genes by a fur titration assay. J Mol Biol 236, 531-545.

Studier, F. W. \& Moffatt, B. A. (1986). Use of bacteriophage T7 RNA polymerase to direct selective high-level expression of cloned genes. J Mol Biol 189, 113-130.

Takeshita, S., Sato, M., Toba, M., Masahashi, W. \& HashimotoGotoh, T. (1987). High-copy-number and low-copy-number plasmid vectors for lac $Z$ alpha-complementation and chloramphenicol- or kanamycin-resistance selection. Gene 61, 63-74.

Thompson, D. K., Beliaev, A. S., Giometti, C. S., Tollaksen, S. L., Khare, T., Lies, D. P., Nealson, K. H., Lim, H., Yates, J., III \& other authors (2002). Transcriptional and proteomic analysis of a ferric uptake regulator (fur) mutant of Shewanella oneidensis: possible involvement of fur in energy metabolism, transcriptional regulation, and oxidative stress. Appl Environ Microbiol 68, 881-892.
Touati, D., Jacques, M., Tardat, B., Bouchard, L. \& Despied, S. (1995). Lethal oxidative damage and mutagenesis are generated by iron in delta fur mutants of Escherichia coli: protective role of superoxide dismutase. J Bacteriol 177, 2305-2314.

Tuanyok, A., Kim, H. S., Nierman, W. C., Yu, Y., Dunbar, J., Moore, R. A., Baker, P., Tom, M., Ling, J. M. \& Woods, D. E. (2005). Genomewide expression analysis of iron regulation in Burkholderia pseudomallei and Burkholderia mallei using DNA microarrays. FEMS Microbiol Lett 252, 327-335.

Vasil, M. L. (2007). How we learnt about iron acquisition in Pseudomonas aeruginosa: a series of very fortunate events. Biometals 20, 587-601.

Visca, P., Leoni, L., Wilson, M. J. \& Lamont, I. L. (2002). Iron transport and regulation, cell signalling and genomics: lessons from Escherichia coli and Pseudomonas. Mol Microbiol 45, 1177-1190.

Wilderman, P. J., Sowa, N. A., FitzGerald, D. J., FitzGerald, P. C., Gottesman, S., Ochsner, U. A. \& Vasil, M. L. (2004). Identification of tandem duplicate regulatory small RNAs in Pseudomonas aeruginosa involved in iron homeostasis. Proc Natl Acad Sci U S A 101, 9792-9797.

Edited by: J. W. B. Moir 